\title{
Role of social skills in improving the women's marital adjustment in the city of Sanandaj
}

\author{
Ladan Nasri ${ }^{1, \star}$, Hasan Babaee ${ }^{2}$ \\ ${ }^{1}$ Economics and Social Development, Tehran University, Tehran, Iran \\ ${ }^{2}$ Department of Law, Payame Noor University, Tehran, Iran \\ *E-mail address: nasri.ladan@yahoo.com
}

\begin{abstract}
This research was done with the aim of studying the role of social skills in improving the women's marital adjustment and its specialized objectives are addressing the role and effect of cognitive, behavioral, and emotional skills, women's age, acquaintance with the husband before marriage, work place of the husband, woman's educational level, their employment, and number of their children on their marital adjustment (dependent variable). The theoretical framework of this study consists of theories of Nay's social exchange, Coffman's dramatic theory, the models of Elizabeth Bath's roles, Godden's pure relationship, Coleman's social-cognitive capital, Framo's internal conflict solution, Negee's ethical criteria, Guttmann's elimination of conflicts, Buchner's self -disclosure, Ellis's illogical and inflexible thoughts, Mitchell's family life cycle, and Bourdieu's cultural capital. The survey method research was employed in this study and the statistical universe consisted of women aged 20-55 and the sample size of 365 people were selected through the multi stage cluster and random sampling. Research instrument was questionnaires, asking questions related to social skills through researcher made questionnaires and to measure the marital adjustment variable the Lock-Wallace marital adjustment questionnaire was applied. Research findings suggest that there is a significant relationship between variables of social skills (cognitive, behavioral and emotional variables) on one hand, and marital adjustment of the other hand, so that by increasing cognitive behavioral and emotional skills, the degree of marital adjustment will also rise. Also, there is a meaningful relationship among the age difference between husbands and wives, number of their children, education level, and women's profession on one hand and marital adjustment on the other hand. Also, the marital adjustment of women in terms of acquaintance before marriage and the spouse's were place was different, that is the ones who were acquainted with each other and the work place of their spouses were in Sanandaj had higher marital durability.
\end{abstract}

Keywords: Social skills; Marital adjustment; Cognitive; behavioral and emotional skills; LockWallace marital adjustment

\section{INTRODUCTION}

One of the most important factors that affects that survival and continuation of life is healthy relations based on the mutual understanding and compatibility of the members of the family, and the couples in particular. Marital adjustment is one of the most important factors 
affecting life performance. This term is related with most terms such as "marital satisfaction", "marital cheerfulness", "marital success" and "marital durability". Since these terms show only one aspect of marriage, marital adjustment is a multi- aspect term that elucidates multiple levels of marriage and it is a process that is created during the couples' lives, because it necessitates adaptation of tastes, recognition of personality traits, creation of behavioral rules and formation of communicative patterns. Hence, marital adjustment is an evolutionary process between woman and man (Ghorbanalipour, 2008). Marital adjustment is a situation in which man and woman have in most of times a feeling of satisfaction and fortune of each other. Adjustment in marriage occurs through mutual interest, care for each other, acceptance and understanding the latter and meeting the needs and desires (Sedaghat and Lotfollahi, 2010).

Marital adjustment affects the quality of parents' life, health levels, life satisfaction, degree of loneliness feeling, nurturing and education children, social relations and inclination to social deviancies. As the first human institution, family plays the most important role in the mental, social and cultural personality of the children. As children enter the society either for education or for doing social activities at higher ages levels, these impacts will be transferred to the society as a whole. As a result, a healthy family will have a main role in the special health. Since the family itself is affected by the society and other social bodies like the media, hence, attention to the health and internal environment of the families and the couples as determining force and the way family moves in that direction will be of utmost importance.

Observing the marital life in recent years at the social level and the literature existing in this regard are indicative of the fact that in all family lives, there is no an environment of comfort, and love and mutual understanding does not always exist among all the couples. In other words, life satisfaction for men and women will not be accomplished henceforth. As a result, some of the families are living in a stressful and tension-filled environment where in addition to the impact on ethics, the daily base behaviors of the couples, will impact on the ethics and personality of the children. We witness that all year long divorce rate is increased for as much as 13-17\% in our country (Kave, 2007). In the nine months of 2011, we experienced 96502 cases of divorce that on this basis the crude rate resulting from the national divorce registration was $1 / 7$ per thousand (Iranian statistics center, 14/12/2011). According to the personal status organization of Sanandaj in 2010, from 21526 cases of marriage, 3271 cases led to divorce and in 2011 from 21313 cases, 3478 cases were divorces cases. Particularly, studies have shown that the most prevalent problem of the families referring to the service and intervention centers has been the problem of communication problems. Of course, if in a society the divorce statistics is trivial, this does not mean successful marriages and marital adjustment. Most couples are living in families where mental divorce prevails. In other words, there is no physical and emotional relation between the man and woman, rather life moves ahead by way of coercion and the minimum interaction.

Many factors including the social skills affect the quality of marital adjustment .Social skills are a set of competencies that increases the adaptability power and positive and efficient behavior of the person, so that the person will be able to accept his responsibilities as social roles without hurting others and to effectively deal with daily life problems and challenges (Irvani and Ebrahimi, 2010). Life skills will increase the personal adjustment with the environment and challenges, rendering the person to address effectively his professional, educational and familial environments. Life skills are directed at promoting the social mental abilities and as a result, they will satisfy the mental and social as well as physical needs. Training life skills will enable the person to transfer his knowledge, values and attitudes to potential acts, meaning the person should learn what he does and how he does it. 
When a relation takes place evidently, explicitly and out of sensual feeling, the relation will be bolstered. However, if the relation is established defensively, aggressively and ineffectively, it will be undermined and when the trend of relations is obstructed extensively, the relation will rapidly collapse. Where there are no communicative skills, love between the couples will largely decline. To have a satisfactory relations, ways should be discovered that would at least help us bridge the inter personal gaps between the spouses (Bolton, 2007). Thus, the general question raised in here is whether social skills as variables could affect the marital adjustment. Adjustment affects different aspects of life quality in the marital relations including: the couples' mental health, life satisfaction, life expectancy, the quality of the parents' performance, degree of loneliness feeling, nurturing and education children, social relations and inclination to social deviancies. As the first human institution, family plays the most important role in the mental, social and cultural personality of the children .Thus, considering the significance of the marital adjustment in the family life and finally the balance of the family and the community, recognition of adaptation categories between man and woman and solutions, skills and techniques of creation and survival are of the most important categories that would lead us to this main subject. One of the reasons that elucidates the necessity of the current paper for us is the increased rate of divorce in Iran and the universe under study so that we witness that all year long divorce rate is increased for as much as $13-17 \%$ in our country (Kave, 2007). In the nine months of 2011, we experienced 96502 cases of divorce that on this basis the crude rate resulting from the national divorce registration was 1/7 per thousand (Iranian statistics center, 14/12/2011).

According to the personal status organization of Sanandaj in 2010, from 21526 cases of marriage, 3271 cases led to divorce and in 2011 from 21313 cases, 3478 cases were divorces cases. Particularly, studies have shown that the most prevalent problem of the families referring to the service and intervention centers has been the problem of communication problems. Of course, if in a society the divorce statistics is trivial, this does not mean successful marriages and marital adjustment. Most couples are living in families where mental divorce prevails. In other words, there is no physical and emotional relation between the man and woman, rather life moves ahead by way of coercion and the minimum interaction. Meantime, divorce and collapse of the family, while disturbing the emotionalmental balance of the members of the society and the families, will lead to emergence of many social problems. Divorce, as a reason or subject of social anomalies, is itself subject to the couples' inappropriate interactions. Negative implications of divorce involves disturbances for the social context and children and families who are related with it in such areas of mental, behavioral and socio-economic aspects in particular while investigating it is of high importance. Thus, it is necessary to deal with the reason of marital maladjustment with failure in marriages through a pathological perspective. If the coupes have social skills in communicative styles could every well sole most of their life problems? Many factors including the social skills affect the quality of marital adjustment. Social skills are a set of competencies that increases the adaptability power and positive and efficient behavior of the person, so that the person will be able to accept his responsibilities as social roles without hurting others and to effectively deal with daily life problems and challenges so that man can accomplish his mental health in connection with other humans, society, culture and his environment positively and effectively.

Results by Yalsin et al (2007) titled as the impact of communication training plan of the couples on the couples' marital adjustment indicated that the training plan could have positive impacts on the marital adjustment levels and could led to correction of behaviors among the coupes in the long run (Quoted by Shakerian, 2012). Given the complexity and multidimensional sense of adjustment and factors relation hereafter, the research theoretically attempts to deal the sociological approach and inter personal relations. Also, environmentally 
speaking, this study addressed the variable of the couples' employment and its impacts on the quality of marital adjustment. A variable that seemingly could affect the marital adjustment of the women in Sanandaj.

In relation with social skills (cognitive, behavioral and sensual skills ) with the marital adjustment of women under study, a fusion of theories of Nay's social exchange, Coffman's dramatic theory, the models of Elizabeth Bath's roles, Giddens ' pure relationship, Coleman's social-cognitive capital, Framo's internal conflict solution, Negee's ethical criteria, Guttmann's elimination of conflicts ,Buchner's self-disclosure, Ellis's illogical and inflexible thoughts, Mitchell's family life cycle, and Bourdieu's cultural capital was applied and all of them emphasize on the role of social skills on the marital adjustment and these theorists maintain those who have social skills are better at handling their marital affairs.

The main objective of this research is to investigate the relation of social skills with improving marital adjustment of the women in Sanandaj in 2013. Research hypotheses:

1. There is relation between the woman cognitive skills and marital adjustment.

2. There is relation between the woman behavioral skills and marital adjustment.

3. There is relation between the woman sensual skills and marital adjustment.

4. There is relation between the woman age and marital adjustment.

5. There is relation between the couples' age difference and marital adjustment.

6. There is relation between the couples' educational level and marital adjustment.

7. There is relation between the number of children and marital adjustment.

8. There is relation between the work place of the spouse and marital adjustment.

\section{RESEARCH METHODOLOGY}

The survey method research was employed in this study and the statistical universe consisted of women aged 20-55 and the sample size of 365 people were selected through the multi stage cluster and random sampling. To collect data, three questionnaires were made use of research made questionnaire of demographic characteristics, research made questionnaire of social skills and the standard questionnaire of marital adjustment. To assess the questionnaire's validity, the nominal validity was applied. Nominal validity depends on the mental assessment of the researcher of the validity of the measurement tool. For this, the researcher consults experts (judges). If there is consensus among the judges, the researcher concludes the questionnaire has nominal validity. A lack of consensus among the judges will hurt the nominal validity (Frankfurt and Nachmias, 2011). In this paper, the advisor and professors are provided with the prepared questionnaire and upon approval, their consensus and validity about the indices are applied.

$\mathrm{T}$ determine, also, the reliability level of the measurement tools and to estimates the internal consistency of the questionnaires, the Cronbach's alpha was used, To investigate the Cronbach alpha of the research questionnaire, first a sample including 30 questionnaires was given out among the audience of the questionnaire randomly. A pretest was through the SPSS and the Cronbach alpha of any of the ineopendnat and dependent variables estimated. In another definition, marital adjustment can $b$ defined as marital satisfaction, overall agreement, companionship level and togetherness as well as the sexual relations being satisfactory among the couples and this has two functions of continuation and satisfaction . To evaluate this concept, a shortened 10 question scale on the Lock-Wallace marital adjustment (1959) was applied The test score equals a sum of scores and its range is from 2 to 158. This test has higher validity for the recognized groups and distinguishing scores for the adjusted and maladjusted couples. 
The scores of this test are highly correlated with those of the test "Lock-WallaceWallace marital prediction". This result is indicative of a simultaneous validity of it. The mentioned test is a scale for predicting the future adjustment. Internal consistency estimation, using the Brown-Spearman formula was very good and the correlation coefficient between the two halves was $90 \%$. This test shows that to what extent the respondent is agreeable with her spouse with regards to a number of activities found to be fundamental in the marital adjustment. This questionnaire was translated by Mazaheri and applied on a sample of Iranian couples. He has reported the reliability of this test by applying the split half method at $90 \%$ (Shakerian, 2012). In this research, the scoring method of the test was changed and the questions were measured by the five degree Lickert scale.

\section{RESEARCH FINDINGS}

Table 1. The Pearson correlation test among the social skills (cognitive, behavioral and emotional skills), age, couples' age difference, number of children, women's educational level with the marital adjustment.

\begin{tabular}{|c|c|c|c|}
\hline Variable 1 & Variable 2 & $\begin{array}{c}\text { Pearson correlation } \\
\text { coefficient amount }\end{array}$ & Sig. \\
\hline $\begin{array}{c}\text { Women's cognitive } \\
\text { skills }\end{array}$ & Marital adjustment & $0 / 626$ & $0 / 000$ \\
\hline $\begin{array}{c}\text { Women's behavioral } \\
\text { skills }\end{array}$ & Marital adjustment & $0 / 921$ & $0 / 000$ \\
\hline $\begin{array}{c}\text { Women's emotional } \\
\text { skills }\end{array}$ & Marital adjustment & $0 / 887$ & $0 / 000$ \\
\hline Age & Marital adjustment & $-0 / 66$ & $0 / 000$ \\
\hline $\begin{array}{c}\text { Couples' age } \\
\text { difference }\end{array}$ & Marital adjustment & $-0 / 43$ & $0 / 000$ \\
\hline $\begin{array}{c}\text { Number of children } \\
\text { Momen's educational } \\
\text { level }\end{array}$ & Marital adjustment & $-0 / 25$ & $0 / 000$ \\
\hline \begin{tabular}{c} 
Womital adjustment \\
\hline
\end{tabular}
\end{tabular}

In accordance with Table 1. The Pearson correlation test results indicate that there is a link between the women's marital adjustment and their cognitive skills. According to the correlation coefficient signal $(0 / 626)$ being positive, there is a direct relation between the two variables. In other words, as one of them increases, the other increases. Thus, this hypothesis is approved.

The second hypothesis: the Pearson correlation test for the relation between the women's behavioral skills and marital adjustment indicates there is a relation between these two variables. According to the correlation coefficient signal $(0 / 921)$ being positive, there is a direct relation between the two variables. In other words, as one of them increases, the other increases. Thus, this hypothesis is approved.

The third hypothesis: the Pearson correlation test for the relation between the women's emotional skills and marital adjustment indicates there is a relation between these two variables. According to the correlation coefficient signal $(0 / 887)$ being positive, there is a 
direct relation between the two variables. In other words, as one of them increases, the other increases. Thus, this hypothesis is approved.

The fourth hypothesis: the Pearson correlation test for the relation between the women's age and marital adjustment indicates there is a relation between these two variables. According to the correlation coefficient signal (-0/66) being negative, there is an indirect relation between the two variables. In other words, as one of them increases, the other decreases.

The sixth hypothesis: It is observed that the significance level of the test $(0 / 000)$ is less than $0 / 05$, hence, the null hypothesis is rejected and one can with $95 \%$ certainty say that there is a significant relation between the two variables of couples' age difference and marital satisfaction. According to the correlation coefficient signal $(-0 / 43)$ being negative, there is an indirect relation between the two variables. In other words, as one of them increases, the other decreases.

The eighth hypothesis: There is a significant relation between the number of children and marital the adjustment. In accordance with the correlation coefficient sign (-0/25) being negative, there is an indirect relation between the two variables. In other words, as one of them increases, the other decreases. Hence, women with higher number of children, have lower marital adjustment.

Ninth hypothesis: There is a significant relation between the women's educational level and marital adjustment. The correlation coefficient sign of $(0 / 63)$ indicates there is a direct relationship between the two variables. In other words, as one of them increases, the other increases.

Table 2. T-test between the spouse's work place and marital satisfaction.

\begin{tabular}{|c|c|c|c|c|c|c|c|}
\hline Variable & Frequency & Average & $\begin{array}{c}\text { Standard } \\
\text { deviation }\end{array}$ & F & Sig. & T & Sig, \\
\hline $\begin{array}{c}\text { Sanandaj } \\
\text { local }\end{array}$ & 195 & $47 / 29$ & $10 / 37$ & $6 / 771$ & $0 / 010$ & & \\
\hline $\begin{array}{c}\text { Sanandaj } \\
\text { non-local }\end{array}$ & 170 & $38 / 11$ & $9 / 44$ & & & $8 / 796$ & $0 / 000$ \\
\hline
\end{tabular}

In line with the table the $T$ level is $8 / 796$ with the significance level of $0 / 000$ being less than $0 / 05$, hence, we can refuse the assumption of variance equality. In other words, groups are different significantly in terms of marital adjustment and because the average of the first group (locals to Sanandaj) is greater than that of the second group, we can state that people whose spouse's working place is in Sanandaj are found to have higher marital adjustment.

\section{CONCLUSIONS}

Findings revealed that there is a significant relation between the cognitive-social skills of women and their marital adjustment. For example, as the cognitive skills of women increase marital adjustment will increase also. Hence, women who can better identify and control for their own emotions are aware of their spouses' feelings and needs. They are skilled in mutual confidence and are familiar with the problem solving skills. They recognize themselves as equal against others and respect others. They are truly satisfied with their 
marital lives. These findings reaffirms the theories of Coffman's dramatic theory, the models of Elizabeth Bath's roles, Godden's pure relationship, Coleman's social-cognitive capital.

Responding the main second hypothesis, there is a meaningful relation between the women's marital adjustment and their behavioral skills. For example, as the behavioral skills of women increase marital adjustment will increase also. Hence, women who are good listeners will meet the needs and expectations of their spouses, observe the independence of their spouses, and respect their views, assume their responsibilities in the area of parental, spousal affairs and are totally pleased with their decision making while solving their conflicts. They spend their leisure time together and acknowledge the efforts by the latter while they spend special times talking with their husbands.

These findings support the theories of Coffman's dramatic and role difference based on collaboration and correspondence in the three fold arenas of action and responsibility acceptance within the role areas, Elizabeth's shared roles paradigm based on the role of attending to the spouse, consultation in decision making, spending leisure time and the shared family affairs and the Coleman's cognitive and social capital based on the intragroup capital role such as; the couples' mutual expectations of each other, respect for the latter's opinions, Guttmann's conflict solution based on the ability to solve the couples' conflicts and avoiding rebuke and reproach. These data are also in line with those of Sedaghat and Lotfollahi (2010).

The findings of the their main hypothesis suggest there is a link between the sensual skills of women and marital adjustment. For example, an increase in the emotional skills of women will cause to increase their marital adjustment. Hence, women that enjoy skills like expression of affection, empathy, intimacy and self-revelation, sacrifice and devotion, have better marital adjustment. This result corresponds with the Giddens' pure theory, involving affection, intimacy and self-revelation, sacrifice and devotion. Data suggest that there is a meaningful relation between the age and marital adjustment. The Pearson correlation test with the coefficient of $-0 / 66$ suggest that there is a negative an inverse relation between the two variables. In this way, as age goes up, marital adjustment will decline. Age for different reasons have determining roe in the couples' marital adjustment, because people have different needs at different ages and have different capacities for meeting their needs and their taste will be changed during life. The findings of this research are in concert with those of the research by Sedaghat and Lotfollahi, (2010). There is a significant difference between the couples' age difference and marital adjustment.

In this way, as he age difference increases the marital adjustment will decline. Hence, peoples' expectations and their attitudes will be changed as time lapses. People have different thinking and attitudes at different ages. Huge age difference affects the marital satisfaction and adjustment. Generally speaking, we can say that though research done in the area of age difference between the man $\mathrm{d}$ woman have not reported consistent results, they have all stated totally that the age of the spouses being close would have an effective role in the marital adjustment. However, it should not be suspected that any marital bond will be weakened by an age difference while existence of attachments and high educations will have positive impacts on the marital satisfaction and adjustment .

There is a significant relation between the marital adjustment and spouse's work place and groups are significantly different in terms of average scores of marital adjustment. Generally, people whose spouses are working in their own cities are found to have more marital adjustment. There is a link between the number of children and the marital adjustment. In accordance with the correlation coefficient sign $(-0 / 25)$ being negative, there is an indirect relation between the two variables. In other words, as one of them increases, the other decreases. Hence, women with higher number of children, have lower marital adjustment. 
High number of children due to high demands and expectations of their parents will cause to change the decision making processes regarding more independence to the children and this will affect their mental capacity and educational levels. This issue supports the theory of Mitchell's family life cycle based on the effective role of number of children on the increasing expectations, giving more independence to them, decision about the educational progress and the couples' relations. There is a relation between the women's educational level and their marital adjustment. This result is in concordance with the theory of the Pear Bourdieu's cultural capital based on the role of cognitive abilities in solving family conflicts and marital adjustment.

\section{Research recommendations}

A) The young people that have the intention of marriage, must first be trained to recognize themselves and realize their universal attitudes, be familiar with their real expectations deeply and then find a mate for themselves so that there is closeness between a thinking world and their cultural capital. Also, the newly married couples should be trained to get to know their thinking and cultural worlds and themselves and then they should attempt to get close via their values and mutual understanding. Finally, the couples spending years of shared life should commence activities to get close to each other by self-recognition and conversations so that they have satisfaction with their lives. It is natural under such circumstances healthy and confortable environments are established in families where they have mental health.

B) In accordance with the importance of the role of social skills in marital adjustment, it is imperative to have more training courses for the youth willing to get married. These programs will boost such programs as: 1 . Trainthe couples as to how to express and listen to the internal feelings and experiences of each other. 2. identify their own feelings and thoughts, 3. promote problem solving skills, 4. quality of more intimate behavior, 5. express affection, positive verbal and non -verbal behaior6.express love and interest and attach importance to the latter in sexual affairs, 7. avoid reproach and rebuke, 8. skills of how to express internal needs not expressed before, 9. train a proper way of criticizing, 10. spend leisure time for more intimacy, 10. train empathy, empathy, is a temporal loving in the world of the latter and moving with the inward intricacy of this world without making judgments and feeling the themes and payments he's hardly aware of however, one should not reveal the feelings, that the person is totally unaware of. Empathy is when a person can comprehend other peoples' success, even when he is not in those situations. Empathy helps people to accept and respect the conditions of other people when he's quite different with them.

C) It is recommended training social skills be considered by the counselor as part of educational curriculum.

D) It is imperative family sociologists be used at the counseling centers for training pre and post marriage conducts.

\section{References}

[1] Irvani M., Ebrahimi J., Journal of Sociology 3 (2010) 111-119.

[2] Bolton R. (2007). Psychology of human relations, trans, by Hamid Reza Sohrabi, Tehran: Roshd publications. 
[3] Shakerian A. (2012). Role of personality and gender aspects in forseeing marital adjustment, Two research and scientific quarterly of the Kermanshah Medical Sciences University, 1: 27- 36.

[4] Sedaghat K., Lotfollahi N., Quarterly of Sociology 3 (2010) 37-49.

[5] Frankfurt Ch., Nechmias D. (2011). Research techniques in sociology, Trans. By Fazel Larijani and Reza Fazeli, Tehran: Soroosh publications.

[6] Ghorbanalipour M. (2008). Efficacy of education on changes and innovations of social life and life satisfaction, Quarterly of psychological and educational sciences at the University of Alzahra, No. 4.

[7] Kave S. (2007). Psychology of spouses' maladjustment, investigation of spouses' communication problems and ways to counter them. Tehran: Sokhan publications.

[8] Audu Andrew Jatau, International Letters of Social and Humanistic Sciences 8(1) (2014) $18-27$.

[9] Rajesh K. Yadav, Nishant Dabhade, International Letters of Social and Humanistic Sciences 10(2) (2014) 181-201.

[10] Benedicta Ehi Momodu, International Letters of Social and Humanistic Sciences 13 (2014) 64-70. 